\section{Australian Journal of \\ Crop Science}

AJCS 15(07):1005-1012 (2021)

doi: 10.21475/ajcs.21.15.07.p3005
AJCS

ISSN:1835-2707

\title{
Antifungal activity and the effect of the essential oil of Lippia origanoides Kunth on Aspergilllus mycotoxins production
}

\author{
Rafaela Magalhães Brandão ${ }^{1}$, Vanuzia Rodrigues Fernandes Ferreira ${ }^{1}$, Luís Roberto Batista ${ }^{2}$, Eduardo \\ Alves $^{3}$, Wilder Douglas Santiago ${ }^{1}$, Richard Bispo Barbosa ${ }^{1}$, Alex Rodrigues Silva Caetano ${ }^{1}$, David Lee \\ Nelson ${ }^{4}$, Maria das Graças Cardoso ${ }^{{ }^{*}}$
}

${ }^{1}$ Chemistry Department, Federal University of Lavras, 37200-900, Lavras, Minas Gerais, Brazil

${ }^{2}$ Department of Food Science, Federal University of Lavras, 37200-900, Lavras, Minas Gerais, Brazil

${ }^{3}$ Department of Phytopathology, Federal University of Lavras, 37200-900, Lavras, Minas Gerais, Brazil

${ }^{4}$ Postgraduate Program in Biofuels, Federal University of Jequitinhonha and Mucuri Valley, 39100-000, Diamantina, Minas Gerais, Brazil

\section{*Corresponding author: mcardoso@ufla.br}

\begin{abstract}
Lippia origanoides (Verbenaceae) is an aromatic plant of great importance in Brazilian medicine. The antifungal and antimycotoxigenic effects of Lippia origanoides essential oil (LEO) on Aspergillus carbonarius, Aspergillus flavus and Aspergillus ochraceus were investigated. The LEO was obtained by hydrodistillation, and it was characterized by GC-FID and GC-MS. The antifungal activity was determined by mycelial growth and mycotoxin and ergosterol assays. Scanning electron microscopy was used to evaluate the effect of the LEO on the plasma membrane of fungi. The main constituents in the LEO were carvacrol $(58.72 \%), \rho$ cymene $(15.37 \%)$ and $\gamma$-terpinene $(12.73 \%)$. Significant fungicidal effects of LEO against $A$. carbonarius $(0.24 \mu \mathrm{L} / \mathrm{mL}), A$. flavus $(0.98 \mu \mathrm{L} / \mathrm{mL})$ and $A$. ochraceus $(0.98 \mu \mathrm{L} / \mathrm{mL})$ were observed. A reduction in the ochratoxin A synthesis that ranged from 92.03 to $98.02 \%$ and from 81.72 to $96.92 \%$ for the fungal species $A$. carbonarius and $A$. ochraceus, respectively, was observed in the presence of LEO. The production of aflatoxin $B_{1}$ and $B_{2}$ was qualitatively inhibited. The biosynthesis of ergosterol was significantly inhibited by the application of LEO, and morphological alterations and damage to the integrity of the fungal cell membrane were observed. The LEO has a high potential for use as an antifungal and antimycotoxigenic agent against $A$. carbonarius, $A$. flavus and $A$. ochraceus.
\end{abstract}

Keywords: antifungals; ergosterol; essential oil; Lippia origanoides Kunth; ochratoxin; aflatoxins.

Abbreviations: $\mathrm{AFB}_{1}$ _aflatoxin $\mathrm{B}_{1} ; \mathrm{AFB}_{2}$ aflatoxin $\mathrm{B}_{2} ; \mathrm{FID}$ flame ionization detector; $\mathrm{GC}$ _gas chromatography; MS_mass spectrometer; OTA_ochratoxin A; SEM_Scanning Electron Microscopy.

\section{Introduction}

Humans are constantly exposed to mycotoxins, mainly through the consumption of contaminated food, but also through inhalation or dermal exposure (Ostry et al., 2017). These substances are secondary metabolites produced by filamentous fungi during growth, and they contaminate the entire food chain and agricultural crops such as coffee, grapes, peanuts, corn and products with a high starch content (Bennet and Klich, 2003; Saldan et al., 2018, Zhang et al., 2017). Mycotoxins pose health risks because of their toxicities, and they can cause mycotoxicosis in the individual who consumes contaminated food and is exposed to toxins (Ostry et al., 2017). The fungus Aspergillus flavus produces aflatoxin $\mathrm{B}_{1}\left(\mathrm{AFB}_{1}\right)$ and aflatoxin $\mathrm{B}_{2}\left(\mathrm{AFB}_{2}\right)$. A. carbonarius and $A$. ochraceus species are considered to be the principal strains capable of producing ochratoxin A (OTA). According to the IARC, OTA exhibits a possible carcinogenic activity in humans (Group 2B), and aflatoxins are classified as natural carcinogenic substances for humans (Group 1) (larc, 1993; larc, 2012).

In addition, filamentous fungi can cause aspergillosis, the most common opportunistic fungal infection in immunosuppressed individuals (Latgé, 1999). Most human infections are caused by Aspergillus fungi. The inhalation of spores produced by these fungi can cause lung diseases ranging from local inflammation of the airways to lifethreatening infections such as allergic bronchopulmonary aspergillosis and invasive arpergillosis (Latgé, 1999; Moazam and Denning, 2017; Negri et al., 2018).

The antifungals available for control of fungal contamination are few compared to those available for bacterial control. Thus, knowledge of the mechanisms of action of antifungals is important for the correct choice of treatment, and they are divided into classes according to their mode of action. Antifungals that interfere with the enzymes involved in the synthesis of ergosterol or sterol itself belong to four classes of compounds: azoles (imidazoles: ketoconazole and miconazole; triazoles: itraconazole, fluconazole and voriconazole), polyenes (amphotericin B and nystatin), fluopyrimidine (5-fluorocytosine) and allylamines (terbinafine) (Ghannoum and Rice, 1999; Pilmis et al., 2015; Tatsumi et al., 2013). However, several fungus strains have developed strategies to deal with these antifungals, rendering 
them resistant to these substances. In addition, the literature reports the fact that synthetic antifungal compounds are considered to be toxic and can cause undesirable side effects (Negri et al., 2018; Prasad et al., 2016). Thus, the search for new substances capable of complementing conventional therapy and reverting resistance represents the challenge. Essential oils are complex mixtures of chemical constituents originating from a variety of aromatic plants that exhibit antimicrobial properties against various pathogenic microorganisms (Bakkali et al., 2008; Raut and Karuppayil, 2014). Therefore, the use of these natural products might be an alternative for traditional treatment. The species Lippia origanoides, belonging to the family Verbenaceae, is a very aromatic shrub distributed throughout South America, mainly in the Amazon region and northeastern Brazil. It is popularly known as rosemary d'angola and is more commonly used in popular medicine and as a spice for food preparations (O'Leary et al., 2012; Menezes et al., 2018; Oliveira et al., 2014; Pascual et al., 2001). Considering essential oils as a source of potential antimicrobial substances, this study sought to analyze the chemical composition of LEO and to evaluate the antifungal and antimycotoxigenic activities against $A$. carbonarius, $A$. flavus and $A$. ochraceus.

\section{Results and discussion}

\section{Yield and chemical composition of the essential oil}

The yield of the LEO was $1.06 \%( \pm 0.10)(w / w)$. Thirteen compounds were identified from the analysis of volatile compounds in the LEO, and the principal compound was carvacrol (58.72\%), a phenolic monoterpene (Table 1). Other major constituents were the monoterpene hydrocarbons $\rho$ cymene $(15.37 \%)$ and $\gamma$-terpinene $(12.73 \%)$, and the sesquiterpene trans- $\beta$-caryophyllene (4.88\%).

The data for the compounds in the LEO partially corroborated those found by Teixeira et al. (2014), who analyzed the essential oil from the same plant species collected in the Medicinal Plants Garden of UFLA. They determined that carvacrol (41.51\%), $\rho$-cymene (18.36\%), $\gamma$-terpinene $(17.03 \%)$ and thymol (4.86\%) were the principal constituents. Betancur-Galvis et al. (2011) collected nine samples of $L$. originoides from four regions of Columbia and encountered carvacrol (12.2 - 46.2\%), $\rho$-cymene (8.8 - 15.7\%), $\gamma$-terpinene (4.5 to $13.2 \%), \beta$-caryophyllene (9.4-11.3\%), $\alpha$-phellandrene (8.7-9.9\%), and thymol (9.2-54.5\%) as the principal components.

The compositions of essential oils can be determined by genetic factors, but other factors can cause significant changes in the composition of secondary metabolites. These factors include the season of the year, age and stage of development of the plant, period of collection, moisture, temperature, soil nutrition, and harvesting and postharvest processes (Gobbo-Neto and Lopes, 2007).

\section{Effect of essential oil on mycelial growth}

The effect of different concentrations of the LEO on the development of $A$. carbonarius, $A$. flavus and $A$. ochraceus is shown in Fig. 1. The results indicated that the LEO inhibited the mycelial growth of the fungus in a dose-dependent manner. A significant inhibition of mycelial growth $(p<0.05)$ at the lowest concentrations tested was observed when it was compared to the effect of the control. The highest concentrations completely suppressed the growth of $A$. carbonarius, $A$. flavus and $A$. ochraceus, with MFC values of $0.24 ; 0.98$, and $0.98 \mu \mathrm{L} / \mathrm{mL}$, respectively. The growth of $A$. carbonarius, $A$. flavus and $A$. ochraceus was inhibited by the
LEO concentrations in the ranges of 20.37 to $100 \%, 31.48$ to $100 \%$ and 26.85 to $100 \%$, respectively.

The antifungal activity of essential oils might be related to synergism between the constituents through their complex chemical compositions. Moreover, this action might also depend on the presence of certain chemical functions present in the compounds (Bakkali et al., 2008). The lipophilic character of the hydrocarbon backbone and the hydrophilic character of the functional groups are of great importance. These substances trigger toxic effects on the structure of the fungal cell wall and cytoplasmic membrane, resulting in leakage of cytoplasmic constituents, alteration in fluidity and permeability, and, consequently, interaction with organelles. Constituents with functional groups, such as phenols, alcohols and aldehydes, can interact with membraneassociated enzymatic proteins and inhibit their production or activity (Kalemba and Kunicka, 2003).

\section{Antimycotoxigenic activity}

The anti-ochratoxigenic properties of the LEO tested at various concentrations below the MFC are shown in Fig. 2 . The effects on the inhibition of OTA synthesis were observed in a dose-dependent manner, and the concentrations of LEO tested significantly reduced the production of OTA. The only statistically significant difference was observed with the concentration of $3.91 \mu \mathrm{L} / \mathrm{mL}$, for which a slightly smaller effect than those observed with the other concentrations tested with both fungi was seen. High degrees of OTA inhibition were observed in $A$. carbonarius and $A$. ochraceus, ranging from 92.03 to $98.02 \%$ and 81.72 to $96.92 \%$, respectively.

Anti-aflatoxigenic properties were observed for the LEO, and the biosynthesis of $\mathrm{AFB}_{1}$ and $\mathrm{AFB}_{2}$ in $A$. flavus was qualitatively inhibited. The presence of $A F B_{1}$ and $A F B_{2}$ in the inoculum of $A$. flavus without the treatment was determined by comparison with the $A \mathrm{FB}_{1}$ and $\mathrm{AFB}_{2}$ standards because it presented two characteristic spots with $R_{f}$ value $_{s}$ and fluorescence spots similar to commercial standards. These two characteristic spots were not observed in different treatments, suggesting that LEO was efficient in inhibiting the biosynthesis of the mycotoxins produced by $A$. flavus.

The interference of the essential oil in the production of mycotoxins is a consequence of the decrease in the number of mycelia because these toxic substances are mainly produced by the mycelial structures of which the filamentous fungi are constituted (Hua et al., 2014). In addition, the antifungal and antimycotoxigenic activities of essential oils are related to the restriction of sporulation in filamentous fungi because, when the fungi are exposed to essential oils, the production of secondary metabolites (mycotoxins) and fungal infections can be prevented (Basak, 2018). The results found in this work are justified because a relationship of the inhibition of OTA, $\mathrm{AFB}_{1}$ and $\mathrm{AFB}_{2}$ with the mycelial growth and sporulation of the fungi was observed.

Currently, studies present hypotheses that explain the mode of action of essential oils in suppressing mycotoxins by interfering in stages of the metabolic pathway. Prakash et al. (2015) suggest that the essential oil acts by binding enzymes responsible for the catabolism of lipids and carbohydrates of toxigenic fungi. The decrease at the transcriptional level of genes regulating secondary metabolism and the mechanism of virulence indicate changes in important enzymes that are involved in the metabolism of fungal lipids and proteins (Oliveira et al., 2020a; Oliveira et al, 2020b). According to the authors, this action of essential oils is related to their antimycotoxigenic properties. 


\section{Scanning Electron Microscopy (SEM)}

The morphological changes to A. carbonarius, A. flavus and $A$. ochraceus treated with $0.06,0.24$ and $0.24 \mu \mathrm{L} / \mathrm{mL}$, respectively, of the LEO are shown in Fig. 3 . The presence of the LEO in the culture medium resulted in a morphology different from that of the fungal control. Marked changes were observed in the entire length of the hyphae and in the apical regions.

A normal morphology and the healthy development of conidial and conidiophore heads, with hyphae of a linear and regular shape, could be seen in both controls (Fig. 3A, C and E). However, this morphology changed after exposure to different concentrations of the LEO. Deformation and craters (Fig. 3B), disruption, loss of integrity in the conidial head (Fig. 3D), and no conidial head formation (Fig. 3F) resulted from exposure to the LEO. Anomalies in the morphology of the hyphae, which had a smaller diameter, aggregates of wilted hyphae, wrinkled, empty, collapsed and flattened hyphae (Fig. 3B, D and F) resulted as a consequence of LEO treatment. The characteristic morphology with uniform and robust hyphae of constant diameter and smooth surface was observed in the mycelium of the fungi in the fungal control. In contrast, normal morphological structures changed in the presence of LEO. The results found in this work are similar to other studies in which the presence of essential oil causes morphological changes in the fungi, causing shrinkage, lysis, reduction of indefinite cell sizes and structures (Bomfim et al., 2020; Danielli et al., 2018; Kohiyama et al., 2015; Nerilo et al., 2016). These changes in fungal structures are related to the lipophilic properties of the constituents present in essential oils that interact with ergosterol, as seen in this study. This interaction can affect the enzymatic reactions that regulate cell wall synthesis and, consequently, change the permeability of the cytoplasmic membrane leading to loss of cell integrity and leakage of ions and metabolites (Koyiama et al., 2015; Nerilo et al., 2016).

\section{Effect of essential oil on ergosterol synthesis}

Ergosterol is a steroid that is present in the fungus membrane. This compound participates as a fluid modulator of the fungal membrane. Any effect on this secondary metabolite causes an imbalance in the fluidity and promotes intracellular homeostatic changes. It is a fundamental compound for the survival of the microorganism (He et al., 2014). In this study, ergosterol synthesis by all Aspergillus species was inhibited in the presence of LEO, with a significant difference between the different treatments $(p<0.05)$. This fact indicated a dose-dependent effect, in addition to total inhibition of steroid biosynthesis (Table 2). These results clearly indicate the antifungal effect of LEO, and previous studies have also highlighted the efficiency of essential oils on ergosterol, where a change in cell structure can make the fungus' intracellular environment incompatible with its survival (Bomfim et al., 2020; Kohiyama et al., 2015).

Farag et al. (1989) noted that there is a relationship between antimicrobial activity and chemical structures of the principal compounds in essential oils. Generally, the effect of an essential oil can be attributed to the compounds that have an aromatic moiety containing a polar functional group. According to the authors, the $\mathrm{OH}$ substituents of phenolic compounds are quite reactive and capable of forming hydrogen bonds with the active sites of the target enzymes, thereby increasing the effect of the antimicrobial activity of the active principle. Thus, the presence of the $\mathrm{OH}$ group in the principal (carvacrol, an oxygenated monoterpene with a phenol structure) and minor constituents of the LEO might be responsible for the antifungal activity.

Much attention has currently been given to the biological potential of herbal products to be used as an alternative to conventional products by the pharmaceutical and food industry. Essential oils have been extensively researched for their efficiency as antifungal agents and for presenting ecological characteristics. In this study, the antifungal efficiency of the LEO against fungal isolates of the genus Aspergillus was seen. In addition, antimycotoxigenic properties were observed for the essential oil, wherein the syntheses of ochratoxin $A$ and aflatoxins $B_{1}$ and $B_{2}$, which contaminate food and are harmful to humans, were suppressed.

\section{Validation of ergosterol method}

\section{Selectivity}

No interfering substances were observed in the samples at the retention time of ergosterol, as can be seen by comparing the chromatogram of the sample without the analyte with that of the same sample fortified with the ergosterol standard at a $1000 \mu \mathrm{g} / \mathrm{L}$ concentration (Fig. 4)

\section{Linearity}

The linearity of the method was evaluated by estimating the determination coefficient for the analytical curve obtained by linear regression $(y=23070,29 x-37036,07)$. The determination coefficient was 0.9999 , which demonstrates the strong linear correlation between the concentration of the compound analyzed and the area of the peak (Anvisa, 2003).

\section{Precision}

The CV of $1.84 \%$ was obtained for the ergosterol analysis at the concentration of $10 \mu \mathrm{g} / \mathrm{L}, 1.17 \%$ at the concentration of $250 \mu \mathrm{g} / \mathrm{L}$ and $1.49 \%$ at the concentration of $1000 \mu \mathrm{g} / \mathrm{L}$ by the repeatability test. In the test performed for the evaluation of the intermediate precision, a CV of $2.44 \%$ was obtained in the analysis of ergosterol at the concentration of $10 \mu \mathrm{g} / \mathrm{L}, 2.03 \%$ at the concentration of $250 \mu \mathrm{g} / \mathrm{L}$ and $0.64 \%$ at the concentration of $1000 \mu \mathrm{g} / \mathrm{L}$. In both tests, the CVs were lower than the $5 \%$ limit for the compound analyzed, as recommended by Anvisa (2003). Thus, a high degree of precision for the ergosterol analysis in fungal samples was obtained with the method.

\section{Limits of detection and quantification}

The LD and LQ for ergosterol were 1.461 and $3.523 \mu \mathrm{g} / \mathrm{L}$, respectively. These values were lower than those found by Yuan et al. (2007) $(L D=0.02 \mu \mathrm{g} / \mathrm{mL} ; L Q=0.07 \mu \mathrm{g} / \mathrm{mL})$ and by Kohiyama et al. (2015) $(\mathrm{LD}=0.15 \mu \mathrm{g} / \mathrm{mL} ; \mathrm{LQ}=10 \mu \mathrm{g} / \mathrm{mL})$. This fact demonstrates that the method for the analysis of ergosterol in fungal samples after treatments with essential oils was highly sensitive. Ribani (2004) attributed these differences in the parameters to the different chromatographic conditions, such as the apparatus or the methods adopted for the quantification of the compound.

\section{Accuracy}

Based on the acceptable limits for the percentage of recovery $(70-120 \%)$, the method presented good recovery for 
Table 1. Chemical composition of the essential oil from Lippia origanoides Kunth.

\begin{tabular}{|c|c|c|c|c|}
\hline Constituents & RT & RI reference* & RI calculated & $(\%)$ \\
\hline$\alpha$-Tujene & 6.632 & 924 & 925 & 0.96 \\
\hline$\alpha$-Pinene & 6.854 & 932 & 933 & 0.45 \\
\hline Myrcene & 8.702 & 988 & 989 & 1.19 \\
\hline$\alpha$-Phellandrene & 9.156 & 1002 & 1008 & 1.09 \\
\hline$\alpha$-Terpinene & 9.587 & 1014 & 1018 & 1.50 \\
\hline$\rho$-Cymene & 9.854 & 1020 & 1025 & 15.37 \\
\hline Limonene & 10.038 & 1024 & 1030 & 0.11 \\
\hline$\gamma$-Terpinene & 11.179 & 1054 & 1058 & 12.73 \\
\hline Terpinen-4-ol & 16.513 & 1174 & 1183 & 0.13 \\
\hline Carvacrol & 21.936 & 1298 & 1299 & 58.72 \\
\hline Trans- $\beta$-Caryophylene & 27.183 & 1417 & 1419 & 4.88 \\
\hline D-Germancrene & 29.864 & 1484 & 1481 & 0.21 \\
\hline Caryophylene oxide & 30.528 & 1582 & 1583 & 0.10 \\
\hline Total & & & & 97.44 \\
\hline
\end{tabular}

RT: retention time; RI: retention index. * Adams (2007) mass-spectral retention index library.

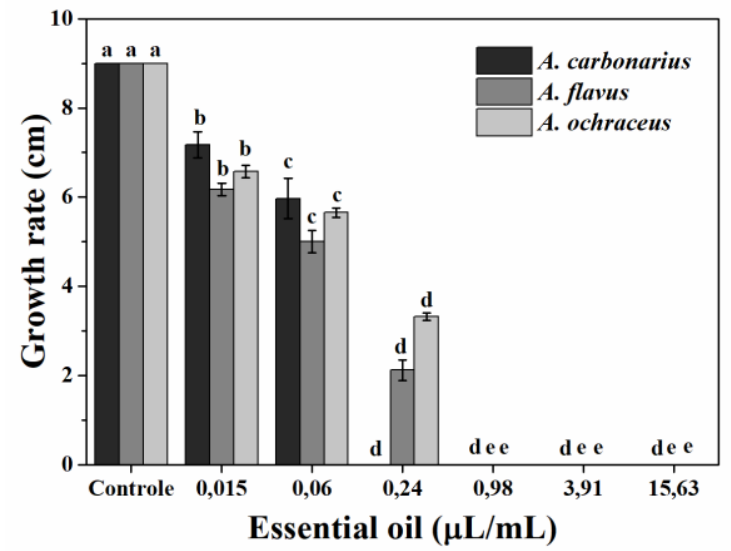

Fig 1. Antifungal activity of different concentrations of the essential oil from Lippia origanoides on the mycelial growth rate of fungi of the genus Aspergillus. The values in the columns of each treatment for each fungus that are followed by different letters are significantly different $(p<0.05)$.

Table 2. Effect of the essential oil from Lippia origanoides on the synthesis of ergosterol.

\begin{tabular}{|c|c|c|c|c|c|c|}
\hline \multicolumn{3}{|c|}{ Essential oil } & \multicolumn{4}{|c|}{ Ergosterol inhibition } \\
\hline \multirow{2}{*}{$\begin{array}{l}\text { concentration } \\
(\mu \mathrm{L} / \mathrm{mL})\end{array}$} & \multicolumn{2}{|c|}{ Aspergillus carbonarius } & \multicolumn{2}{|c|}{ Aspergillus flavus } & \multicolumn{2}{|c|}{ Aspergillus ochraceus } \\
\hline & $(\%)$ & $\mu g / L$ & $(\%)$ & $\mu g / L$ & $(\%)$ & $\mu \mathrm{g} / \mathrm{L}$ \\
\hline Controle & $0^{c}( \pm 0.00)$ & 1184.95 & $0^{c}( \pm 0.00)$ & 1132.22 & $0^{c}( \pm 0.00)$ & 1083 \\
\hline 0.015 & $84.08^{b}( \pm 0.81)$ & 188.52 & $73.34^{d}( \pm 0.65)$ & 301.87 & $62.82^{d}( \pm 0.70)$ & 402.67 \\
\hline 0.06 & $87.19^{b}( \pm 0.42)$ & 151.66 & $84.64^{c}( \pm 0.33)$ & 173.85 & $70.08^{c}( \pm 0.72)$ & 323.99 \\
\hline 0.24 & $100^{\mathrm{a}}( \pm 0.00)$ & 0 & $90.19^{b}( \pm 0.76)$ & 111.08 & $73.55^{b}( \pm 0.70)$ & 286.45 \\
\hline 0.98 & $100^{\mathrm{a}}( \pm 0.00)$ & 0 & $100^{\mathrm{a}}( \pm 0.00)$ & 0 & $100^{\mathrm{a}}( \pm 0.00)$ & 0 \\
\hline
\end{tabular}

*Values with different letters are significantly different $(p<0.05)$.

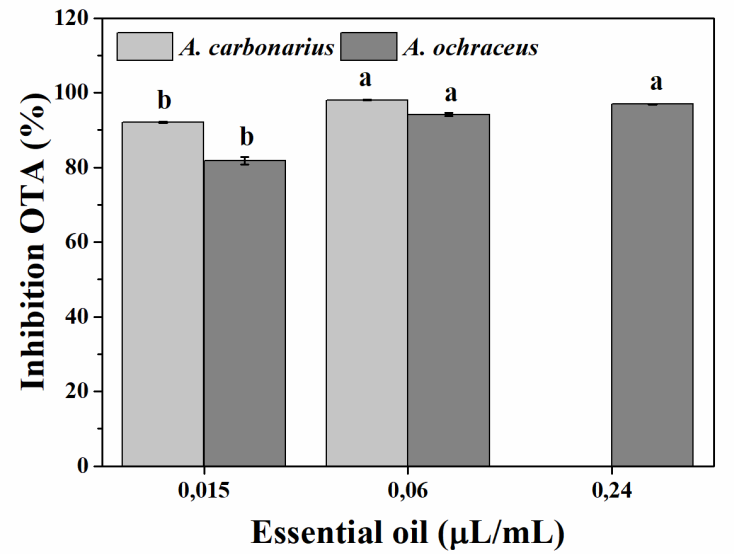

Fig 2. Effect of the essential oil from Lippia origanoides on the production of ochratoxin A by A. carbonarius and A. ochraceus. Statistical differences are represented by different letters $(p<0.05)$. 

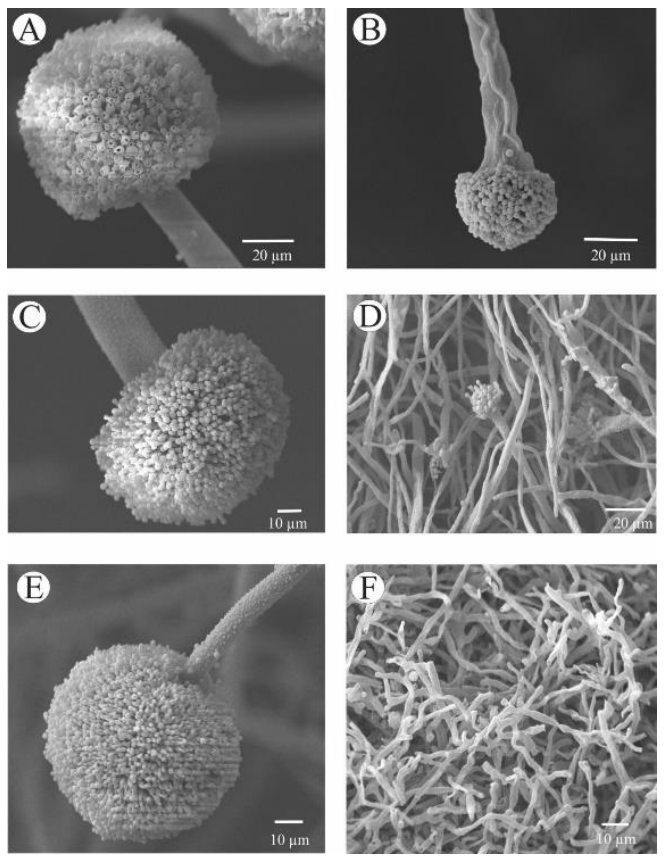

Fig 3. The effects of the essential oil of Lippia origanoides on the morphology of fungi of the genus Aspergillus are illustrated in the electronmicrographs obtained at a magnification of 1500X. (A, C, E) Controls for $A$. carbonarius, $A$. flavus e $A$. ochraceus, respectively. $(\mathrm{B}, \mathrm{D}, \mathrm{F}) \mathrm{A}$. carbonarius, $A$. flavus e $A$. ochraceus, respectively, treated with essential oil.

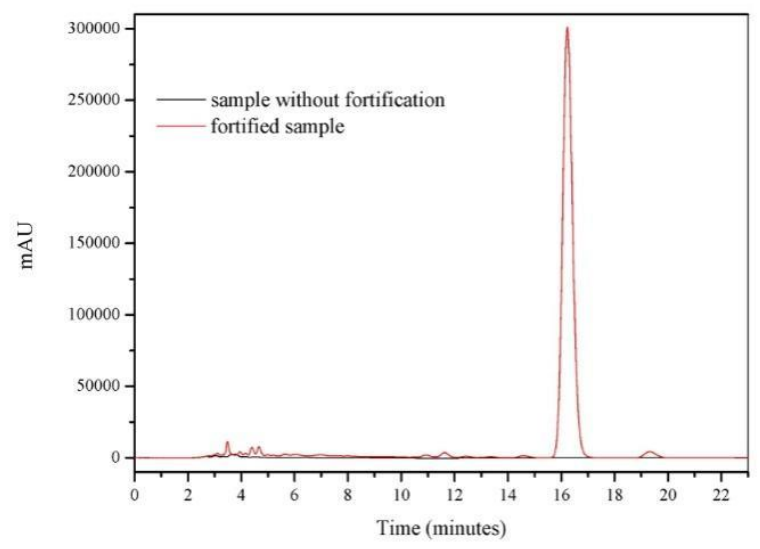

Fig 4. Chromatograms of the ergosterol-free sample and the sample containing $1000 \mu \mathrm{g} / \mathrm{L}$ of the ergosterol standard.

ergosterol: 90.05 - $99.91 \%$ in the $A$. carbonarius sample, 85.32 $-105.32 \%$ in the A. flavus sample and $85.79-99.86 \%$ in the A. ochraceus sample. The partial values and the mean value lay within the acceptable limit range. Yuan et al. (2008) obtained a similar recovery of ergosterol in a range of 99.1 to $101.4 \%$. Kohiyama et al. (2015) obtained a lower recovery $(77.4 \%)$ than that obtained in the present study.

\section{Material and methods}

\section{Plant material and extraction of essential oil}

The leaves of Lippia origanoides were collected at the Medicinal Plants Garden of the Federal University of Lavras (UFLA) (21 $12^{\circ} 40^{\prime \prime} \mathrm{S} 44^{\circ} 57^{\prime} 58^{\prime \prime} \mathrm{W}$ ) in March 2016. The plant material was deposited in the ESAL Herbarium (UFLA) under registration number 23660 . The species was identified by the specialist Dr. Fátima Salimena.

The essential oil was extracted by the hydrodistillation method using a modified Clevenger apparatus (Anvisa, 2010). The yield of the oil was determined according to the method of Pimentel et al. (2006) and expressed as weight of oil per unit weight of plant material on a moisture-free basis.

\section{Chemical characterization of the essential oil}

The chemical composition of the LEO was determined using a gas chromatograph coupled to a mass spectrometer (GC-MS, Shimadzu Corporation, model QP 2010 Plus, Kyoto, Japan) (Adams, 2007). The experimental conditions were the same as those used by Brandão et al. (2020). The acquired and processed data collection was performed using the LabSolutions LC/GC Workstation 2.72. The Van den Dool and Kratz (1963) equation was used for retention index calculation. The identification of the compounds was based on the comparison of their retention indexes with those of the literature (Adams, 2007) and on the comparison of their mass spectra with those of the FFNSC 1.2, NIST 107 and NIST 21 mass spectra libraries. The percentage of the constituents was determined by normalizing the areas (\%) after separation by a gas chromatograph equipped with a flame ionization detector (GC-FID, Shimadzu GC - 2010, Kyoto, Japan) and 
using the same experimental conditions as those used for identification of the constituents in the essential oil.

\section{Microorganisms}

The species of filamentous fungi tested were Aspergillus carbonarius (CCDCA10507), Aspergillus flavus (CCDCA10508) and Aspergillus ochraceus (CCDCA10506), acquired from the Microorganisms Culture Collection in the Laboratory of Mycotoxins and Food Mycology, UFLA. The isolates were transferred to Petri dishes containing Malt Extract Agar medium (MEA, HiMedia Laboratories Pvt. Ltd., Munbai, Índia) and spore solution $\left(10^{6}\right.$ spores $\left./ \mathrm{mL}\right)$ was prepared according to the method of Brandão et al (2020).

\section{Inhibitory effect of the essential oil}

The inhibitory effect of LEO against fungal mycelial growth was evaluated according to the method of Brandão et al. (2020). The LEO was diluted in DMSO and the concentrations tested were $0.015,0.06,0.24,0.98,3.91$ and $15.63 \mu \mathrm{L} / \mathrm{mL}$. The fungal control for the mycelial growth test was performed in medium containing only inoculum without the essential oil. All the plates were incubated in a BOD at $25^{\circ} \mathrm{C}$ for 10 days. After incubation, the fungal growth was determined from the mycelial diameter (in centimeters). The Minimal Fungicidal Concentration (MFC) was considered to be the lowest concentration of essential oil that completely inhibited fungus growth. All treatments and controls were performed in triplicate.

\section{Inhibition of ochratoxin A synthesis}

Samples for the determination of anti-ochratoxigenic activity were prepared using the same culture conditions as those described in the previous section (Inhibitory effect). The inhibition of OTA production in A. carbonarius ( 0.015 and 0.06 $\mu \mathrm{L} / \mathrm{mL}$ ) and $A$. ochraceus $(0.015,0.06$ and $0.24 \mu \mathrm{L} / \mathrm{mL}$ ) by LEO was tested at concentrations below the MFC. OTA extraction was performed according to the method of Passamani et al. (2014) on the $10^{\text {th }}$ day of the incubation of the fungi.

Quantification of OTA was performed using the method standardized by Passamani et al. (2014), and the experimental chromatographic conditions were in accordance with the method of Brandão et al. (2020). OTA retention time was $11 \pm 0.1 \mathrm{~min}$. The external standard method was used for quantification of OTA using a commercially available standard (Sigma-Aldrich ${ }^{\circledR} 202$, São Paulo, Brazil). An analytical curve was obtained by linear regression, correlating the band areas versus the concentrations of the respective standard solutions. The coefficient of determination $\left(R^{2}\right)$ was 0.9999 , and the Limit of Detection and Limit of Quantification were 0.0004 and 0.0016 $\mu \mathrm{g} / \mathrm{g}$, respectively. All the samples and OTA standard solutions were analyzed in triplicate. The following equation was used for the calculation of the inhibition of OTA production (\%) by the essential oil:

$$
I_{\text {OTA }}=\frac{O_{c}-O_{t}}{O_{c}} \times 100
$$

where $\mathrm{Oc}$ is the quantity of ochratoxin produced by the control and $\mathrm{Ot}$ is the ochratoxin produced after treatment with essential oil.

\section{Inhibition of $A F B_{1}$ and $A F B_{2}$ synthesis}

Samples for the determination of anti-aflatoxigenic activity were prepared using the same culture conditions as those described in the section on inhibitory effect of the essential oil. The inhibition of the production of $\mathrm{AFB}_{1}$ and $\mathrm{AFB}_{2}$ in $A$. flavus by the LEO was performed at concentrations of 0.015 ,
0.06 and $0.24 \mu \mathrm{L} / \mathrm{mL}$ (below the MFC). Aflatoxins were extracted according to the method of Passamani et al. (2014) and analyzed by thin layer chromatography according to the method of Brandão et al. (2020).

\section{Scanning Electron Microscopy}

The effect of the essential oil on fungus morphology was evaluated by Scanning Electron Microscopy (SEM) according to the method of Brandão et al. (2020). The samples were prepared using the conditions described in section on inhibitory effect of the essential oil. The concentrations tested were $0.06 \mu \mathrm{L} / \mathrm{mL}$ for $A$. carbonarius and $0.24 \mu \mathrm{L} / \mathrm{mL}$ for A. flavus and $A$. ochraceus.

\section{Inhibition of ergosterol production}

Fungal biomass was obtained by growing $A$. ochraceus and $A$. flavus in YES liquid medium and $A$. carbonarius in CYA liquid medium. LEO was previously diluted in DMSO and added to the liquid media. The concentrations tested were $0.015,0.06$, 0.24 and $0.98 \mu \mathrm{L} / \mathrm{mL}$. DMSO was employed for the negative control. Ten $\mu \mathrm{L}$ of the spore suspension $\left(10^{6}\right.$ spores $\left./ \mathrm{mL}\right)$ was inoculated in Erlenmeyer flasks containing liquid media. Samples were kept in Erlenmeyer flasks at $25^{\circ} \mathrm{C}$ for 10 days in a BOD. After incubation, the contents of the flasks were filtered using filter paper. The wet mycelial biomass was weighed and used for the extraction and quantification of ergosterol.

The ergosterol was extracted according to the method described by Brandão et al. (2020), and analysis was performed on the Shimadzu HPLC chromatograph. The detector was an SPD-M20A diode array. Elution was accomplished with an isocratic system of $100 \%$ methanol (HPLC grade) at a flow rate of $1 \mathrm{~mL} / \mathrm{min}$, injection volume of $20 \mu \mathrm{L}$, and monitoring at $282 \mathrm{~nm}$. To calculate the ergosterol inhibition (\%) by the essential oil, the following equation was used:

$$
I_{\text {Ergosterol }}=\frac{E_{c}-E_{t}}{E_{c}} \times 100
$$

where Ec is the ergosterol produced by the control and Et is the ergosterol produced after treatment with essential oil.

\section{Validation of ergosterol method}

The selectivity, linearity, precision, limit of detection, limit of quantification and accuracy of the method were determined to validate the method to ensure that the results were of good analytical quality (Anvisa, 2003; Ribani et al., 2004; Harris, 2008). To evaluate the selectivity of the method, the matrix without the substance of interest (ergosterol) and the matrix to which the analyte standard was added were compared. Linearity was evaluated by the correlation of the signal (peak area) with the concentration of the species of interest, expressed by the equation of the analytical curve and the respective determination coefficient $\left(R^{2}\right)$.

The precision was determined by the methods of repeatability and intermediate accuracy, in which the coefficients of variation (CV) of a series of measurements by means of the mathematical relationship were determined:

$$
C V(\%)=\frac{S D}{M C D}
$$

where SD is the standard deviation and MCD is the mean concentration measured.

The limit of detection (LD) and limit of quantification (LQ) were determined from the parameters of the analytical curve. They were calculated using the following mathematical relationships: 


$$
\begin{aligned}
L D & =3 x \frac{S}{S} \\
L Q & =10 x \frac{S}{S}
\end{aligned}
$$

where $s$ is the estimated standard deviation of the regression line and $S$ is the angular coefficient of the analytical curve. Accuracy was assessed by means of recovery assays using three randomly chosen samples to which the analyte standard was added in three different concentrations. The recovery was determined by considering the results obtained for the analyte using the following mathematical relationship:

$$
\% \text { Recovery }=\frac{\text { Observed concentration }}{\text { Expected concentration }} \times 100
$$

\section{Statistical analysis}

The experimental design was completely randomized (CRD) with three replicates. The statistical program used was SISVAR (Ferreira, 2011). The data were submitted to analysis of variance and the means were compared by the Tukey test to the level of $5 \%$ probability.

\section{Conclusions}

The principal constituents of LEO were carvacrol, $\rho$-cimene and $\gamma$-terpinene. Fungicidal activity against Aspergillus, inhibition of ergosterol biosynthesis and damage to the integrity of the cell wall and fungal cell membrane were observed for the LEO. Inhibition of the production of mycotoxins ( $A F B_{1}, A F B_{2}$ and OTA) was verified. For the first time, the influence of the LEO on the inhibition of mycotoxin and ergosterol biosynthesis were demonstrated. Inhibition of the biosynthesis of this sterol can indicate a possible mechanism of action of the oil under study. Thus, this study clearly demonstrates that LEO can be considered to be a natural and promising alternative for the treatment and control of filamentous fungi of the genus Aspergillus. It can also be used to control the synthesis of mycotoxins that contaminate food to improve food quality and safety.

\section{Acknowledgements}

This work was supported by Fundação de Amparo à Pesquisa de Minas Gerais (FAPEMIG), the Conselho Nacional de Desenvolvimento Científico e Tecnológico (CNPq) and the Coordenação de Aperfeiçoamento de Pessoal de Nível Superior - Brasil (CAPES) - Finance code 001. The authors thank the organs for the scholarships and financial support, the Central of Analysis and Chemical Prospecting of the Federal University of Lavras for supplying the equipment for chromatographic analyses and the Medicinal Plants Garden of the Federal University of Lavras for providing the plant material

\section{References}

Adams RP (2007) Identification of essential oils componentes by gas chromatography/ mass spectroscopy. Allured Pub Corp, Carol Stream, IL.

Agência Nacional de Vigilância Sanitária (ANVISA) (2010) Métodos de Farmacognosia. In Farmacopeia Brasileira. Fiocruz, Brasília, Brasil.

Agência Nacional de Vigilância Sanitária (ANVISA) (2003) Guia para a avaliação de métodos analíticos e bioanalíticos. $R E n^{\circ}$ 899: 1-12.
Bakkali F, Averbeck S, Averbeck D, Idaomar M (2008) Biological effects of essential oils. Food Chem Toxicol. 46 (2): 446-475.

Basak S (2018) Modelling the effect of betel leaf essential oil on germination time of Aspergillus flavus and Penicillium expansum spore population. LWT-Food Sci Tech. 95: 361366.

Bennett JW, Klich M (2003) Mycotoxins. Clin Microbiol Rev. 16 (3): 497-516.

Betancur-Galvis L, Zapata B, Baena A, Bueno J, Ruíz-Nova CA, Stashenko E, Mesa-Arango AC (2011) Antifungal, cytotoxic and chemical analyses of essential oils of Lippia origanoides H.B.K grown in Colombia. Rev Univ Ind Santander Salud 43 (2): 141-148.

Bomfim NS, Kohiyama CY, Nakasugi LP, Nerilo SB, Mossini SAG, Romoli JCZ, Mikcha JMG, Filho BAA, Jr MM (2020) Antifungal and antiaflatoxigenic activity of rosemary essential oil (Rosmarinus officinalis L.) against Aspergillus flavus. Food Addit Contam A 37 (1): 153-161.

Brandão RM, Ferreira VRF, Batista LR, Alves E, Lira NA, Bellete BS, Scolforo JRS, Cardoso MG (2020) Antifungal and antimycotoxigenic effect of the essential oil of Eremanthus erythropappus on three different Aspergillus species. Flavour Frag J. 35 (5): 524-533.

Danielli LJ, Pippi B, Duarte JA, Maciel AJ, Lopes W, Machado MM, Oliveira LFS, Vainstein MH, Teixeira ML, Bordignon SAL, Fuentefria AM, Apel MA (2018) Antifungal mechanism of action of Schinus lentiscifolius Marchand essential oil and its synergistic effect in vitro with terbinafine and ciclopirox against dermatophytes. J Pharm Pharmacol. 70 (9): 1216 1227.

Farag RS, Daw ZY, Hewedi FM, El-Baroty GSA (1989) Antimicrobial activity of some egyptian spice essential oils. J Food Protect. 52 (9): 665-667.

Ferreira DF (2011) Sisvar: a computer statistical analysis system. Cienc Agrotec. 35 (6): 1039-1042.

Ghannoum MA, Rice LB (1999) Antifungal agents: mode of action, mechanisms of resistance, and correlation of these mechanisms with bacterial resistance. Clin Microbiol Rev. 12 (4): 501-517.

Gobbo-Neto L, Lopes NP (2007) Plantas medicinais: fatores de influência no conteúdo de metabólitos secundários. Quim Nova, 30 (2), 374-381.

Harris DC (2008) Análise química quantitativa. LTC, Rio de Janeiro, Brasil.

He WS, Yin J, Xu HS, Qian QY, Jia CS, Ma HL, Feng B (2014) Efficient synthesis and characterization of ergosterol laurate in a solvent-free system. J Agric Food Chem. 62(48): 11748-11755.

Hua H, Xing F, Selvaraj JN, Wang Y, Zhao Y, Zhou L, Liu X, Liu Y (2014) Inhibitory effect of essential oils on Aspergillus ochraceus growth and ochratoxin A production. PLOS One 9 (9): e108285.

International Agency for Research on Cancer (IARC) (2012) Chemical agents and related occupations. IARC Monographs on the evalution carcinogenic risks to humans 100F: 225-244.

International Agency for Research on Cancer (IARC) (1993) Some naturally occurring substances: food items and constituents, heterocyclic aromatic amines and mycotoxins. IARC Monographs on the evaluation carcinogenic risks to humans. 56: 489-521.

Kalemba DAAK, Kunicka A (2003) Antibacterial and antifungal properties of essential oils. Curr Med Chem. 10 (10): 813829. 
Kohiyama CY, Ribeiro MMY, Mossini SAG, Bando E, Bomfim NS, Nerilo SB, Rocha GHO, Grespan R, Mikcha JMG, Machinski JrM (2015) Antifungal properties and inhibitory effects upon aflatoxin production of Thymus vulgaris L. by Aspergillus flavus Link. Food Chem. 173: 1006-1010.

Latgé JP (1999) Aspergillus fumigatus and Aspergillosis. Clin Microbiol Rev. 12 (2): 310-350.

Menezes PMN, Brito MC, de Paiva GO, dos Santos CO, de Oliveira LM, de Ribeiro LAA, Lima JT, Lucchese AM, Silva FS (2018) Relaxant effect of Lippia origanoides essential oil in guinea-pig trachea smooth muscle involves potassium channels and soluble guanylyl cyclase. J Ethnopharmacol. 220: 16-25.

Moazam S, Denning DW (2017) Aspergillus nodules in chronic granulomatous disease attributable to Aspergillus ochraceus. Med Mycol Case Reports 17: 31-33.

Negri CE, Johnson A, McEntee L, Box H, Whalley S, Schwartz JA, Ramos-Martín V, Livermore J, Kolamunnage-Dona R, Colombo AL, Hope WW (2018) Pharmacodynamics of the Novel Antifungal Agent F901318 for Acute Sinopulmonary Aspergillosis Caused by Aspergillus flavus. J Infect Dis. 217 (7): 1118-1127.

Nerilo SB, Rocha, GHO, Tomoike C, Mossini SAG, Grespan R, Mikcha JMG, Jr MM (2016) Propriedades antifúngicas e efeitos inibitórios sobre a produção de aflatoxina pelo óleo essencial de Zingiber officinale em Aspergillus flavus. Int J Food Sci Tech. 51 (2): 286-292.

O'Leary N, Denham SS, Salimena F, Múlgura ME (2012) Species delimitation in Lippia section Goniostachyum (Verbenaceae) using the phylogenetic species concept. Bot J Linn Soc. 170 (2): 197-219.

Oliveira DR, Leitão GG, Fernandes PD, Leitão SG (2014) Ethnopharmacological studies of Lippia origanoides. Rev Bras Farmacogn. 24 (2): 206-214.

Oliveira RC, Carvajal-Moreno M, Mercado-Ruaro P, RojoCallejas F, Correa B (2020a) Essential oils trigger an antifungal and anti-aflatoxigenic effect on Aspergillus flavus via the induction of apoptosis-like cell death and gene regulation. Food Control 110: 107038.

Oliveira RC, Carvajal-Moreno M, Correa B, Rojo-Callejas F (2020b) Cellular, physiological and molecular approaches to investigate the antifungal and anti-aflatoxigenic effects of thyme essential oil on Aspergillus flavus. Food Chem. 315: 126096.

Ostry V, Malir F, Toman J, Grosse Y (2017) Mycotoxins as human carcinogens-the IARC Monographs classification. Mycotoxin res. 33 (1): 65-73.

Pascual ME, Slowing K, Carretero E, Mata DS, Villar A (2001) Lippia: traditional uses, chemistry and pharmacology: a review. J Ethnopharmacol. 76 (3): 201-214.

Passamani FRF, Hernandes T, Lopes NA, Bastos SC, Santiago WD, Cardoso MG, Batista LR (2014) Effect of temperature, water activity, and $\mathrm{pH}$ on growth and production of ochratoxin A by Aspergillus niger and Aspergillus carbonarius from Brazilian grapes. J Food Protect. 77 (11): 1947-1952.
Pilmis B, Jullien V, Sobel J, Lecuit M, Lortholary O, Charlier C (2015) Antifungal drugs during pregnancy: an updated review. J Antimicrob Chemoth. 70: 14-22.

Pimentel FA, Cardoso MD, Salgado APSP, Aguiar PM, Silva VF, Morais AR, Nelson DL (2006) A convenient method for the determination of moisture in aromatic plants. Quim Nova 29: 373-375.

Prakash B, Kedia A, Mishra PK, Dubey NK (2015) Plant essential oils as food preservatives to control moulds, mycotoxin contamination and oxidative deterioration of agri-food commodities - potentials and challenges. Food Control 47: 381-391.

Prasad R, Shah AH, Rawal MK (2016) Antifungals: mechanism of action and drug resistance. Adv Exp Med Biol. 892: 327349.

Raut JS, Karuppayil SM (2014) A status review on the medicinal properties of essential oils. Ind Crop Prod. 62: 250-264.

Ribani M, Bottoli CBG, Collins CH, Jardim ICSF, Melo LFC (2004) Validação em métodos cromatográficos e eletroforéticos. Quim Nova 27 (5): 771-780.

Saldan NC, Almeida RT, Avíncola A, Porto C, Galuch MB, Magon TF, Pilau EJ, Svidzinski TIE, Oliveira CC (2018) Development of an analytical method for identification of Aspergillus flavus based on chemical markers using HPLCMS. Food Chem. 241: 113-121.

Teixeira ML, Cardoso MDG, Figueiredo ACS, Moraes JC, Assis FA, de Andrade J, Nelson DL, Gomes MS, Souza JA, Albuquerque LRM (2014) Essential oils from Lippia origanoides Kunth. and Mentha spicata L.: chemical composition, insecticidal and antioxidant activities. Am J Plant Sci. 5 (9): 1181-1190.

Tatsumi Y, Nagashima M, Shibanushi T, Iwata A, Kangawa $Y$, Inui F, Siu WJJ, Pillai R, Nishiyama $Y$ (2013) Mechanism of action of efinaconazole, a novel triazole antifungal agent. Antimicrob Agents Ch. 57 (5): 2405-2409.

Van Den Dool H, Kratz P (1963) A generalization of theretention index system including linear temperatureprogrammed gas-liquid partition chromatography. J Chromatogr A 11: 463-471.

Zhang X, Cheng Z, Ma L, Li J (2017) A study on accumulation of volatile organic compounds during ochratoxin a biosynthesis and characterization of the correlation in Aspergillus carbonarius isolated from grape and dried vine fruit. Food Chem. 227: 55-63.

Yuan J, Wang JH, Liu X, Kuang HC, Zhao SY (2007) Simultaneous determination of free ergosterol and ergosteryl esters in Cordyceps sinensis by HPLC. Food Chem. 105 (4): 1755-1759.

Yuan JP, Kuang HC, Wang JH, Liu X (2008) Evaluation of ergosterol and its esters in the pileus, gill, and stipe tissues of agaric fungi and their relative changes in the comminuted fungal tissues. Appl Microbiol Biot. 80 (3): 459465. 